\title{
HUBUNGAN STRATEGI PEMBELAJARAN PEER TEACHING DAN SELF ESTEEM DENGAN MOTIVASI BELAJAR (STUDI KASUS PADA SISWA SMK BOEDI OETOMO PONTIANAK)
}

\author{
Nur Kur'ani ${ }^{1}$ Tuti Fuji Lestari ${ }^{2}$ \\ Email: nurkurani@unmuhpnk.ac.id ${ }^{1}$ \\ Program Studi Psikologi, Universitas Muhammadiyah Pontianak ${ }^{1}$ \\ Program Studi Perikanan, Universitas Muhammadiyah Pontianak ${ }^{2}$
}

\begin{abstract}
Abstrak
Tugas guru yang pertama dan terpenting dalam proses belajar mengajar adalah membangun motivasi belajar siswa. Salah satu strategi yang dapat digunakan guru dalam membangun motivasi belajar siswa yaitu strategi pembelajaran peer teaching. Selain itu self esteem pada diri siswa juga dapat mempengaruhi motivasi belajar siswa. Penelitian ini bertujuan untuk mengetahui apakah ada hubungan antara strategi pembelajaran peer teaching dan self esteem dengan motivasi belajar. Metode penelitian yang digunakan adalah metode penelitian kuantitatif. Subyek penelitian ini adalah siswa kelas X dan XI di SMK Boedi Uetomo Pontianak. Jumlah responden yang diteliti sebanyak 24 orang siswa yang terdiri dari satu (1) kelas dan hanya memiliki satu jurusan yaitu administrasi perkantoran. Penentuan jumlah sampel yang digunakan oleh peneliti dalam penelitian ini adalah metode sensus. Hal ini sering dilakukan bila jumlah populasi relatif kecil yaitu kurang dari 30 orang. Penentuan sampel dalam penelitian ini dilakukan dengan teknik non probably sampling. Hasil penelitian menunjukkan ada hubungan antara strategi pembelajaran peer teaching dan self esteem dengan motivasi belajar yang ditunjukkan dengan koefisien korelasi sebesar $\mathrm{R}=0,509$ dengan $(\mathrm{p})=0,000(\mathrm{p}<0,01)$ dan sumbangan efektif sebesar 25,9\% yang berarti sumbangan pengaruh variabel strategi pembelajaran peer teaching dan self esteem terhadap motivasi belajar sebesar 25,9\% sisanya dipengaruhi oleh variabel lain.

Kata kunci: Peer teaching, Self-Esteem, Motivasi Belajar
\end{abstract}

\begin{abstract}
The first and most important task of the teacher in teaching and learning process is to build student learning motivation. One of the strategies that teachers can use in building student learning motivation is peer teaching learning strategy. In addition, self-esteem in students can also affect student motivation. This study aims to determine whether there is a relationship between peer teaching learning strategies and self-esteem with learning motivation. The research method used was quantitative research methods. The subjects of this study were students of class X and XI at SMK Boedi Uetomo Pontianak. The number of respondents studied were 24 students consisting of one (1) class and only had one department, namely office administration. Determination of the number of samples used by researchers in this study used the census method. It is often done when the population is relatively small, namely less than 30 people. The determination of the sample in this study was carried out by using a non probable sampling technique. The results showed that there was a relationship between peer teaching learning strategies and self esteem with learning motivation as indicated by a correlation coefficient of $R=0.509$ with $(p)=0.000(p$ $<0.01)$ and an effective contribution of $25.9 \%$ that means the contribution of influence peer teaching learning strategy variable and self esteem on learning motivation by $25.9 \%$, the rest was influenced by other variables.
\end{abstract}

Kata kunci: Peer teaching, Self-Esteem, Learning Motivation

PENDAHULUAN

Tugas guru yang pertama dan terpenting dalam proses belajar mengajar adalah membangun motivasi belajar siswa. Motivasi belajar adalah suatu daya penggerak dari dalam individu yang menimbulkan semangat dalam belajar dan bisa menjaga keberlangsungan kegiatan belajar guna tercapainya tujuan yang dikehendaki (Winkel, 2014). Oleh karena 
itu guru harus mempunyai strategi pembelajaran yang menarik minat siswa untuk belajar. Strategi pembelajaran peer teaching dapat digunakan guru untuk meningkatkan motivasi siswa karena bisa meningkatkan komunikasi antar siswa dalam belajar.

Metode pembelajaran tutor sebaya (peer teaching) menurut Arjanggi yang dikutip oleh Fitriyah (2015) adalah metode pembelajaran yang dilakukan dengan cara memberdayakan siswa yang memiliki daya serap tinggi dari kelompok siswa itu sendiri untuk menjadi tutor bagi temantemannya. Siswa yang menjadi tutor bertugas memberikan materi belajar dan latihan kepada teman-temannya yang belum paham terhadap materi atau latihan yang diberikan oleh guru yang dilandasi dengan aturan yang telah disepakati bersama dalam kelompok tersebut. Hubungan teman disini lebih dekat dari pada hubungan guru dengan siswa sehingga peran teman dapat mendukung timbulnya motivasi pada siswa. Selain peer teaching motivasi belajar juga berhubungan dengan self-esteem. Hal ini sejalan dengan penelitian Khoirudin (2018) yaitu terdapat hubungan antara selfesteem dengan motivasi belajar dengan hasil pembelajaran PAI siswa kelas IX SMP PGRI 2 Sukadana.
Berdasarkan hasil observasi pada tanggal 13-14 Agustus 2019 di SMK Boedi Oetomo tim peneliti menemukan perilaku-perilaku yang menunjukkan rendahnya motivasi belajar siswa seperti saat diberi tugas yang sulit siswa tidak bertanya kepada guru dan teman, saat guru bertanya siswa tidak menjawab pertanyaan guru, siswa sering keluar masuk kelas, siswa asal mengerjakan tugas, saat guru menjelaskan siswa ribut sendiri, saat pembelajaran dikelas siswa yang aktif hanya beberapa orang saja. Bila motivasi siswa dalam belajar selalu rendah maka akan berdampak pada diri siswa sendiri yaitu siswa bisa tidak naik kelas dan siswa yang berprestasi rendah akan sulit mencari pekerjaan yang diminati setelah lulus dari SMK karena tidak memiliki keterampilan yang dibutuhkan dalam dunia usaha.

Berdasarkan uraian di atas tim peneliti ingin melihat hubungan antara strategi pembelajaran peer teaching, selfesteem dengan motivasi belajar. Dengan rumusan masalah yaitu apakah terdapat hubungan antara strategi pembelajaran peer teaching, self-esteem dengan motivasi belajar. Adapun tujuan penelitian ini yaitu untuk mengetahui hubungan antara strategi pembelajaran peer teaching, self-esteem dengan motivasi belajar. 


\section{KAJIAN PUSTAKA}

\section{Motivasi Belajar}

Motivasi adalah sesuatu yang menghidupkan (energize), mengarahkan dan mempertahankan perilaku, motivasi membuat siswa bergerak, menempatkan mereka dalam suatu arah tertentu dan menjaga mereka agar terus bergerak (Ormrod, 2009:58). Motivasi menyebabkan terjadinya perubahan energy pada siswa, perilaku yang nampak merupakan hasil observasi dari lingkungan sekitar (Iis, 2005). Motivasi sangat dibutuhkan dalam belajar. Dalam kegiatan belajar motivasi dapat dikatakan sebagai keseluruhan daya penggerak di dalam diri siswa yang menimbulkan kegiatan belajar yang menjamin keberlangsungan kegiatan belajar dan memberikan arah pada kegiatan belajar sehingga tujuan yang dikehendaki bisa tercapai (Sardiman, 2007).

Berdasarkan penjelasan di atas motivasi belajar adalah suatu daya penggerak dari dalam diri siswa ditandai dengan adanya perilaku yang berarah pada tujuan yang memberikan arah pada kegiatan belajar dan bisa menjaga keberlangsungan kegiatan belajar siswa.

Ada tiga faktor yang mempengaruhi siswa dalam belajar, yaitu factor internal, eksternal dan factor pendekatan belajar. Adapun aspek-aspek motivasi belajar terdiri dari enam indicator utama dari Uno (2007) yaitu: 1) Adanya hasrat dan keinginan berhasil; 2) Adanya dorongan dan kebutuhan dalam belajar; 3) Adanya Harapan dan Cita-cita; 4) Adanya penghargaan dalam belajar; 5) kegiatan yang menarik dalam belajar; 6) lingkungan belajar yang kondusif.

\section{Strategi Pembelajaran Peer Tecahing}

Metode pembelajaran tutor sebaya (Peer Teaching) menurut Arjanggi yang dikutip oleh Fitriyah adalah metode pembelajaran yang dilakukan dengan cara memberdayakan siswa yang memiliki daya serap tinggi dari kelompok siswa itu sendiri untuk menjadi tutor bagi temantemannya, siswa yang menjadi tutor bertugas memberikan materi belajar dan latihan kepada teman-temannya yang belum paham terhadap materi atau latihan yang diberikan oleh guru yang dilandasi dengan aturan yang telah disepakati bersama dalam kelompok tersebut. hubungan dengan teman disini lebih dekat dari pada hubungan guru dengan siswa sehingga peran teman dapat mendukung timbulnya motivasi pada siswa (Putri, 2015).

Dari pengertian di atas dapat disimpulkan strategi pembelajaran peer teaching adalah strategi pembelajaran yang digunakan oleh guru dengan memanfaatkan teman-teman sebaya siswa 
yang memiliki daya serap tinggi dari kelompok siswa itu sendiri untuk menjadi tutor bagi teman-temannya dengan aturan yang telah disepakati bersama dalam kelompok tersebut sehingga siswa tidak merasa malu untuk bertanya.

Strategi pembelajaran peer teaching meliputi tiga (3) hal pokok yaitu: 1) perencanaan tutor sebaya; 2) pelaksanaan tutor sebaya; 3 ) evaluasi tutor sebaya (Hamka, 2014).

\section{Self Esteem}

Penilaian seseorang secara umum terhadap dirinya baik berupa penilaian negatif maupun positif yang akhirnya menghasilkan perasaan beharga atau berguna dalam menjalani kehidupan disebut self esteem. Siswa yang self esteemnya tinggi tidak mudah terpengaruh oleh penilaian orang lain mengenai sifat dan kepribadiannya, baik itu positif maupun negatif (Wahdania, 2017).

Anak-anak dengan self-esteem tinggi secara konsisten menunjukkan kinerja yang lebih tinggi dibandingkan mereka yang self esteemnya rendah, baik dibidang pendidikan maupun pekerjaan (Gross, 2013). Jika siswa menilai secara positif terhadap dirinya, maka ia menjadi percaya diri dalam mengerjakan hal-hal yang ia kerjakan dan memperoleh hasil yang positif pula (Sarwono, 2018).
Adapun Aspek-aspek harga diri menurut Coopersmith (dalam sriati, 2008) adalah kekuasaan (power), keberartian (significance), kebajikan (Virtue), Kemampuan (competence).

Berdasarkan beberapa penjelasan di atas dapat disimpulkan bahwa harga diri ialah penilaian siswa terhadap dirinya sendiri yang menunjukkan sejauh mana siswa percaya bahwa dirinya mampu, beharga dan berarti dalam hubungan dnegan orang lain. Adapun salah satu alat ukur yang sering digunakan untuk mengukur harga diri secara eksplisit adalah skala Ronsenberg's self-esteem (Sarwono, 2018).

\section{METODE PENELITIAN}

Metode penelitian yang digunakan adalah metode kuantitatif dengan pendekatan statistik. Adapun pengumpulan data penelitian dilakukan dengan menggunakan skala dan dokumentasi. Variabel dalam penelitian ini terdiri dari: 1) variabel bebas yaitu strategi pembelajaran peer teaching dan self esteem, sedangkan 2) variabel terikat yaitu motivasi belajar.

Populasi dalam penelitian ini terdiri siswa kelas X dan kelas XI di SMK Boedi Oetomo Pontianak yang berjumlah 24 siswa yang terdiri dari satu kelas yang hanya memiliki satu jurusan yaitu administrasi perkantoran. Penentuan 
jumlah sampel yang digunakan oleh peneliti dalam penelitian ini adalah metode sensus. Hal ini sering dilakukan bila jumlah populasi relatif kecil yaitu kurang dari 30 orang. Penentuan sampel dalam penelitian ini dilakukan dengan teknik non probably sampling.

Adapun tahapan dalam penelitian ini terdiri dari persiapan penelitian, penentuan sampel penelitian kemudian mempersiapkan insrumen penelitian, melakukan penelitian dan olah data

Analisis data menggunakan analisis regresi ganda dengan program SPPS 16. Analisis terhadap data dilakukan secara kuantitatif deskriptif. kemudian peneliti melakukan analisis intrumen yaitu melakukan perhitungan uji validitas strategi pembelajaran peer teaching, self esteem dan motivasi belajar menggunakan bantuan program komputer SPPS.16.00. Uji validitas item digunakan untuk mengetahui seberapa cermat suatu aitem dalam mengukur apa yang ingin diukur (Priyatno, 2018). Uji coba alat ukur dilakukan terhadap siswa kelas " $X$ " dan XI di SMK Muhammadiyah Pontianak pada tanggal 27 Agustus 2020 oleh seorang guru. Perhitungan uji validitas skala strategi pembelajaran peer teaching, self esteem dan motivasi belajar dilakukan dua tahapan hingga skala yang dianalisis tidak terdapat aitem yang gugur artinya semua aitem dalam skala memiliki nilai validitas lebih dari $r$ tabel. Setelah dilakukan uji validitas pada skala strategi pembelajaran peer teaching sebanyak 11 (sebelas) aitem yang dinyatakan valid. Begitu juga pada skala self esteem dilakukan uji validitas dan hasilnya sebanyak 5 (lima) aitem yang dinyatakan valid. Lebih lanjut uji validitas juga dilakukan pada skala motivasi belajar hasilnya sebanyak 9 (sembilan) aitem yang dinyatakan valid dan digunakan untuk mengambil data penelitian. Setelah melakukan uji validitas baru kemudian dilakukan uji reliabilitas menggunakan program computer SPPS.16.00. Uji reliabilitas digunakan untuk mengetahui keajekan atau konsistensi alat ukur yang biasanya menggunakan kuesioner (Priyatno, 2018).

Berdasarkan hasil pengujian reabilitas instrumen dengan menggunakan SPSS 16.00 diperolehlah nilai coefisien cronbach's alfa untuk strategi pembelajaran peer teaching, self esteem dan motivasi belajar sebesar 0,873. Ini berarti reabilitasnya sangat bagus karena coefisien cronbach's alfa yang diperoleh dari hasil perhitungan $>0,60$ maka dapat disimpulkan bahwa aitem yang digunakan untuk mengukur variabel strategi pembelajaran peer teaching, self esteem dan motivasi belajar sudah reliabel artinya 
aitem pertanyaan yang dipakai untuk mengukur strategi pembelajaran peer teaching, self esteem dan motivasi belajar telah memiliki konsistensi internal yang baik.

Hasil analisis data menunjukkan ada hubungan antara strategi pembelajaran peer teaching (X1) dan self esteem (X2) dengan motivasi belajar ( $\mathrm{Y}$ ) dengan nilai $\mathrm{R}$ $=0,509$ atau $\mathrm{p}=0,000$. Metode penelitian yang digunakan metode penelitian kuantitatif dengan pendekatan statistik. Metode pengumpulan data yang digunakan peneliti adalah metode skala yaitu: Skala Motivasi Belajar, Skala Strategi Pembelajaran Peer Teaching, Skala Self Esteem. Bentuk skala pada penelitian ini menggunakan penskalaan model likert yang memiliki empat alternative jawaban yang sudah tersedia yaitu SS (sangat setuju), S (setuju), TS (tidak setuju), STS (sangat tidak setuju). Rentang skor dalam penelitian ini 1-4. Skala likert digunakan untuk mengukur sikap, pendapat dan persepsi seseorang atau sekelompok orang tentang fenomena sosial. Berdasarkan analisis terhadap 24 siswa (16 siswa perempuan dan 8 siswa laki-laki) diperoleh deskripsi penelitian sebagai berikut:

Adapun uji prasyarat analisis dilakukan dalam penelitian ini yaitu uji normalitas dan uji linearitas menggunakan SPSS 16.00 for windows berikut tabel hasil uji Normalitas dan uji linearitas.

Tabel 1. Hasil Uji Normalitas

\begin{tabular}{|c|c|c|c|c|c|c|}
\hline & \multicolumn{3}{|c|}{ Kolmogorov-Smirnov $^{\mathrm{a}}$} & \multicolumn{3}{|c|}{ Shapiro-Wilk } \\
\hline & Statistic & df & Sig. & Statistic & $\mathrm{df}$ & Sig. \\
\hline $\begin{array}{l}\text { Unstandardized } \\
\text { Residual }\end{array}$ & .130 & 24 & $.200^{*}$ & .957 & 24 & .377 \\
\hline
\end{tabular}

Sumber: SPSS 16.00 tahun 2020

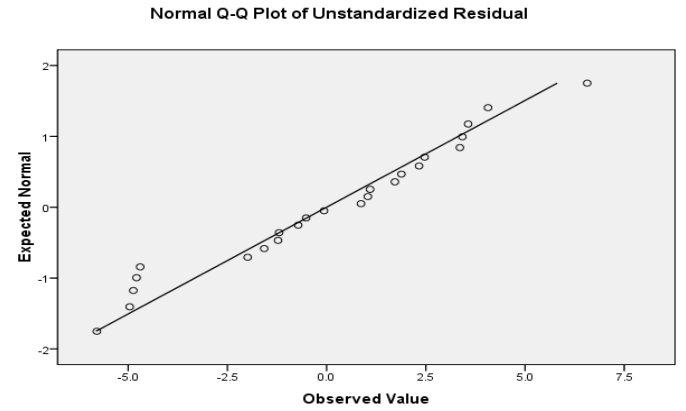

Gambar 1. Hasil Uji Normalitas

Berdasarkan hasil uji normalitas di atas signifikansi kolmogorove sebesar 0,20 menunjukkan data strategi pembelajaran peer teaching, self esteem dan motivasi belajar berdistribusi normal. Berdasarkan gambar di atas untuk melihat normalitas data distribusi data normal jika tidak tersebar disekitar garis dan mengikuti arah diagonal garis. Hal ini menunjukkan bahwa data strategi pembelajaran peer teaching, self esteem dan motivasi belajar dinyatakan normal. Selanjutnya dilakukan uji linearitas dengan program SPSS 16.00 for windows. Hasilnya menunjukkan hubungan antara variabel bebas dan variabel terikat bersifat linear sebagai berikut:

Tabel 2. Hasil Uji Linearitas 
Strategi Pembelajaran Peer Teaching dengan Motivasi Belajar

\begin{tabular}{|cl|r|r|r|r|r|}
\hline & & $\begin{array}{c}\text { Sum of } \\
\text { Squares }\end{array}$ & df & $\begin{array}{c}\text { Mean } \\
\text { Square }\end{array}$ & F & Sig. \\
\hline Y* X1 Between Groups & (Combined & 149.167 & 10 & 14.917 & 1.006 & .486 \\
& ) & & & & & \\
& Linearity & 85.260 & 1 & 85.260 & 5.748 & .032 \\
& $\begin{array}{c}\text { Deviation } \\
\text { from }\end{array}$ & 63.906 & 9 & 7.101 & .479 & .864 \\
& Linearity & & & & & \\
Within Groups & & 192.833 & 13 & 14.833 & & \\
Total & & 342.000 & 23 & & & \\
\hline
\end{tabular}

Sumber: SPSS 16.00 tahun 2020

Tabel 3. Hasil Uji linearitas

Self esteem dengan Motivasi Belajar

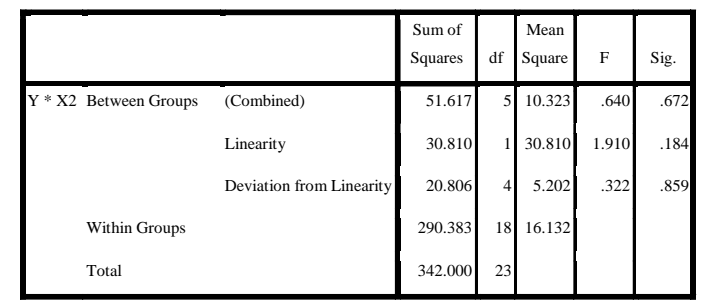

Berdasarkan hasil uji linearitas di atas dapat dilihat pada output anova tabel. Dapat diketahui bahwa nilai signifikansi pada kolom deviation from linearity sebesar 0,864 (Y dan X1) dan 0,859 (Y dan X2). Signifikan lebih dari 0,05 sehingga dapat disimpulkan antara variabel strategi pembelajaran peer teaching dan motivasi belajar terdapat hubungan yang linear begitu juga self esteem berhubungan dengan motivasi belajar. Selanjutnya dilakukan analisis regresi berganda. Analisis regresi berganda digunakan untuk menguji pengaruh variabel bebas terhadap variabel terikat. Perhitungan berdasarkan data primer yang diperoleh dari penyebaran skala online melalui google questioner. Hasilnya menunjukkan ada hubungan antara variabel bebas dan variabel terikat sebagai berikut:

\section{Variables Entered/Removed ${ }^{b}$}

\begin{tabular}{|l|l|l|l|}
\hline Model & $\begin{array}{c}\text { Variables } \\
\text { Entered }\end{array}$ & $\begin{array}{c}\text { Variables } \\
\text { Removed }\end{array}$ & \\
\hline 1 & $\mathrm{X} 2, \mathrm{X} 1^{\mathrm{a}}$ & & Method \\
\hline
\end{tabular}

a. All requested variables entered.

b. Dependent Variable: Y

Model Summary ${ }^{b}$

\begin{tabular}{|r|r|r|r|r|r|}
\hline Model & $\mathrm{R}$ & $\mathrm{R}$ & $\begin{array}{c}\text { Adjusted } \mathrm{R} \\
\text { Square }\end{array}$ & $\begin{array}{c}\text { Std. Error } \\
\text { of the } \\
\text { Square }\end{array}$ & $\begin{array}{r}\text { Durbin- } \\
\text { Watson }\end{array}$ \\
\hline 1 & $.509^{\mathrm{a}}$ & .259 & .189 & 3.474 & 2.294 \\
\hline
\end{tabular}

a. Predictors: (Constant), X2, X1

b. Dependent

Variable: Y

\section{ANOVA $^{b}$}

\begin{tabular}{|c|c|c|c|c|c|}
\hline Model & $\begin{array}{l}\text { Sum of } \\
\text { Squares }\end{array}$ & df & $\begin{array}{l}\text { Mean } \\
\text { Square }\end{array}$ & $\mathrm{F}$ & Sig. \\
\hline $\begin{array}{ll}1 & \text { Regressio } \\
& \mathrm{n}\end{array}$ & 88.605 & 2 & 44.302 & $\begin{array}{r}3.67 \\
2 \\
\end{array}$ & $.043^{\mathrm{a}}$ \\
\hline Residual & 253.395 & 21 & 12.066 & & \\
\hline Total & 342.000 & 23 & & & \\
\hline
\end{tabular}

a. Predictors: (Constant), X2,

$\mathrm{X} 1$

b. Dependent Variable: Y

Coefficients $^{\mathbf{a}}$

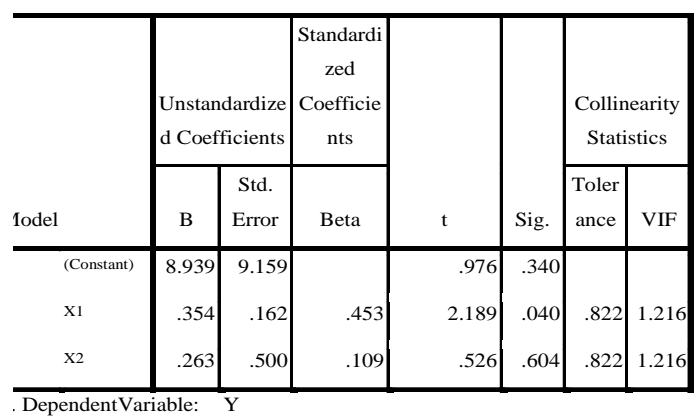


HASIL DAN PEMBAHASAN

Analisis data untuk menguji hubungan antara strategi pembelajaran peer teaching dan self esteem dengan motivasi belajar menggunakan analisis regresi ganda dua predictor dan hasil analisis menunjukkan koefisien regresi (R) $=0,509$ koefisien determinasi $\left(\mathrm{R}^{2}\right)$ sebesar 2,59 artinya secara simultan strategi pembelajaran peer teaching dan self esteem memberikan sumbangan efektif sebesar $25,9 \%$ terhadap motivasi belajar. semakin baik strategi pembelajaran peer teaching dan self esteem maka semakin baik pula motivasi belajar, demikian juga sebaliknya semakin kurang baik strategi pembelajaran peer teaching dan self esteem maka semakin rendah pula motivasi belajar siswa.

Hasil penelitian menunjukkan ada hubungan antara strategi pembelajaran peer teaching, self esteem dengan motivasi belajar yang ditunjukkan dengan koefisien korelasi sebesar $\mathrm{R}=0,509$ dengan $(\mathrm{p})=$ 0,000 dan sumbangan efektif sebesar 2,59 yang berarti semakin tinggi strategi pembelajaran peer teaching, self esteem maka motivasi belajar siswa juga tinggi.

Sumbangan efektif strategi pembelajaran peer teaching, self esteem dalam menjelaskan motivasi belajar sebesar $2,59 \%$, sehingga masih ada $7,41 \%$ variabel lain yang mungkin dapat menjelaskan faktor-faktor lain yang mempengaruhi motivasi belajar. berdasarkan uraian di atas dapat disimpulkan bahwa strategi pembelajaran peer teaching dan self esteem merupakan salah satu factor yang mendukung motivasi belajar.

Hasil penelitian ini mendukung hasil penelitian yang dilakukan oleh Fitriyah (2015) yang mengatakan bahwa terdapat pengaruh metode pembelajaran tutor sebaya (peer teaching) terhadap motivasi belajar siswa. Berdasarkan uraian di atas dapat disimpulkan bahwa strategi pembelajaran peer teaching merupakan salah satu factor yang mendukung motivasi belajar. Khoirudin (2018) juga mengatakan bahwa terdapat hubungan antara self esteem dengan motivasi belajar. Semakin tinggi self esteem maka semakin tinggi motivasi belajar. Hal ini berarti strategi pembelajaran peer teaching dan self esteem secara bersama-sama mempunyai hubungan dengan motivasi belajar.

\section{PENUTUP}

\section{Kesimpulan}

Berdasarkan hasil penelitian tentang hubungan antara strategi pembelajaran peer teaching dan self esteem dengan motivasi belajar pada siswa SMK Boedi Oetomo Pontianak yang dilakukan pada 24 responden yaitu siswa SMK Boedi 
Oetomo Pontianak dapat disimpulkan sebagai berikut: 1. Ada hubungan positif antara strategi pembelajaran peer teaching dan self esteem dengan motivasi belajar; 2 . Strategi pembelajaran peer teaching dan self esteem berpengaruh pada motivasi belajar tapi tidak besar hanya 2,59 sehingga masih ada factor lain lagi yang lebih mempengaruhi motivasi belajar seperti factor internal dan eksternal sebanyak $7,41 \%$; 3 . Perlu adanya strategi pembelajaran yang tepat dalam proses belajar mengajar di kelas untuk meningkatkan motivasi belajar.

\section{Saran}

\section{Bagi Guru}

Hasil Penelitian ini dapat digunakan sebagai bahan masukan oleh guru untuk memperbaiki strategi Pembelajaran di kelas agar siswa lebih termotivasi dalam belajar. Selain itu dalam mengajar guru diharapkan untuk memperhatikan karakteristik tiap siswa dan materi yang akan diberikan kepada siswa serta memperhatikan strategi pembelajaran supaya dapat meningkatkan self-esteem siswa sehingga membuat siswa termotivasi dalam belajar.

\section{Bagi Siswa}

Hasil penelitian ini dapat digunakan sebagai bahan masukan kepada siswa untuk menambah pengetahuan para siswa mengenai self-esteem pada diri siswa. Walaupun self esteem ini ternyata tidak begitu mempengaruhi motivasi belajar siswa tapi setidaknya berpengaruh pada diri siswa. Sehingga siswa bisa belajar memahami strategi pembelajaran selain peer teaching yang dapat mempengaruhi motivasi belajar siswa.

\section{Peneliti Selanjutnya}

Hasil penelitian ini menunjukkan bahwa variable strategi pembelajaran peer teaching dan self esteem ternyata mempengaruhi motivasi belajar siswa hanya $25,9 \%$. Hasil penelitian ini bisa saja berubah dikarenakan saat peneliti melakukan penelitian ini pada saat kondisi pandemic covid 19. Saat penelitian ini berlangsung peneliti melakukan dua kali observasi pertama pada saat penerapan strategi pembelajaran peer teaching, dimana observasi pertama dilakukan saat bulan februari akhir di sekolah pada kelas 2 (dua) SMK dan observasi yang selanjutnya dilakukan secara virtual lewat aplikasi Google meet. Dari observasi tersebut ditemukan saat situasi pandemic strategi pembelajaran peer teaching ini kurang efektif karena kebanyakan siswa di SMK Boedi Oetomo adalah siswa yang berasal dari keluarga kurang mampu yang 
kebanyakan tinggal di luar daerah Kota Pontianak, kebanyakan siswa di SMK Boedi Oetomo ini adalah anak asuh sehingga saat pandemic mereka harus membantu orang tua asuh mereka dirumah, selain itu ada beberapa siswa yang tidak memiliki hand phone sehingga susah dihubungi, dan factor cuaca yang tidak mendukung serta jaringan internet yang tidak stabil. Oleh karena itu jelas disini masih banyak factor lain yang mempengaruhi motivasi belajar siswa. Sehingga para peneliti selanjutnya dapat melakukan penelitian kembali secara lebih mendalam mengenai strategi pembelajaran peer teaching, self esteem dan motivasi belajar

\section{DAFTAR PUSTAKA}

Fitriyah, P. 2015. Pengaruh Metode Pembelajaran Tutor Sebaya (Peer Teaching) terhadap Motivasi dan Hasil Belajar Fisika Siswa Kelas X MAN Baru Jepara. Skripsi (diterbitkan) Yogyakarta. Fakultas Sains dan Teknologi.

Gross, Ricard. 2013. Psychology The Science Of Mind and Behaviour. Edisi Ke Enam. Yogyakarta: Penerbit Pustaka Pelajar.

Hamka, Siregar. 2014. Hubungan Strategi Pembelajaran Tutor Sebaya dan Media Audio Visual dengan Hasil Belajar Bahasa Arab Kelas V di Madrasah Ibtidaiyah Negeri Medan Tembung. Tesis (diterbitkan). Fakultas PAI.
Khoirudin, A. 2017. Hubungan antara Self-Esteem dan Motivasi Belajar Dengan Hasil Belajar pada Mata Pelajaran Pendidikan Agama Islam (PAI) Siswa Kelas IX SMP PGRI 2 Sukadana Tahun Akademik 2017/2018. Tesis (diterbitkan). Metro. Fakultas PAI.

Ormrod, Jeanne Ellis. 2008. Psikologi Pendidikan Membantu Siswa Tumbuh dan Berkembang Edisi Ke Enam Jilid 2. Jakarta: Erlangga.

Priyatno, Dwi. 2018. SPSS Panduan Olah Data Bagi Mahasiswa \& Umum. Yogyakarta: Andi

Sardiman. 2007. Interaksi dan Motivasi Belajar-Mengajar. Jakarta: PT. Raja Grafindo Persada

Sarwono, S,W \& Eko A, M. 2018. Psikologi Sosial Edisi 2. Jakarta: Penerbit Salemba Humanika.

Sugiyono. 2018. Metode Penelitian Kuantitatif. Bandung: Alfabeta

Uno, B. H. 2007. Teori Motivasi dan Pengukurannya: Analisis di Bidang Pendidikan. Jakarta: Bumi Aksara.

Sriati, A. 2008. Harga Diri Remaja. Jatinangor. Universitas Padjadjaran 